\title{
Self-assembly and shape control hybrid carriers based on calcium carbonate and carbon
}

nanodots

Lauth, V. $^{1}$, Loretz, B. ${ }^{2}$, Lehr, C.-M. ${ }^{2,3}$, Maas, M. ${ }^{1,4}{ }^{\text {, Rezwan, K. }}{ }^{1,4}$

${ }^{1}$ Faculty of Production Engineering, Advanced Ceramics, University of Bremen, Bremen, Germany

${ }^{2}$ Department Drug Delivery, Helmholtz-Institute for Pharmaceutical Research Saarland (HIPS), Helmholtz-Centre for Infection Research (HZI), Saarbrücken, Germany

${ }^{3}$ Department of Pharmacy, Saarland University, Saarbrücken, Germany

${ }^{4}$ MAPEX - Centre for Materials and Processes, University of Bremen, Bremen, Germany

*Email: michael.maas@uni-bremen.de

\section{Supplementary Information}

Supporting Information 1: Composition of Hanks balanced salt solution (HBSS).

\begin{tabular}{|l|l|}
\hline Ingredient & Concentration \\
\hline $\mathrm{NaCl}$ & $136.90 \mathrm{mM}$ \\
\hline $\mathrm{KCl}$ & $5.40 \mathrm{mM}$ \\
\hline $\mathrm{NaHCO} 3$ & $4.26 \mathrm{mM}$ \\
\hline $\mathrm{Na} 2 \mathrm{HPO} 4 * 7 \mathrm{H} 2 \mathrm{O}$ & $0.34 \mathrm{mM}$ \\
\hline $\mathrm{KH} 2 \mathrm{PO} 4$ & $0.35 \mathrm{mM}$ \\
\hline Glucose & $5.50 \mathrm{mM}$ \\
\hline $\mathrm{HEPES}$ & $10.00 \mathrm{mM}$ \\
\hline $\mathrm{CaCl} 2$ & $1.26 \mathrm{mM}$ \\
\hline $\mathrm{MgCl} 2 * 6 \mathrm{H} 2 \mathrm{O}$ & $0.50 \mathrm{mM}$ \\
\hline $\mathrm{MgSO} 4 * 7 \mathrm{H} 2 \mathrm{O}$ & $0.40 \mathrm{mM}$ \\
\hline
\end{tabular}



Supporting Information 2: Potentiometric titration of control (Millipore water), $[C D]_{\mathrm{COOH}} 2.3$ and $[\mathrm{CD}]_{\mathrm{COOH}} 0.5$. For sample $[\mathrm{CD}]_{\mathrm{COOH}} 2.3$, which carboxyl content is $11.6 \mathrm{mM}$, the yield is around $0.005 \mathrm{~g}$ 
$\mathrm{L}^{-1}$. The carboxyl concentration can be calculated by diving these two values and results in $2.3 \mathrm{~mol} \mathrm{~g}^{-1}$. Sample $[C D]_{\mathrm{CO}} 0.5$, has the same $11.6 \mathrm{mM}$ carboxyl content but much higher yield, $0.022 \mathrm{~g} \mathrm{~L}^{-1}$, resulting in $0.5 \mathrm{~mol} \mathrm{~g}^{-1}[\mathrm{CD}]_{\mathrm{COOH}}$.

The solid content was measured by evaporating $1 \mathrm{~mL}$ of $C D$ dispersion at $70^{\circ} \mathrm{C}$ for 3 days and weighting the resultant particles.

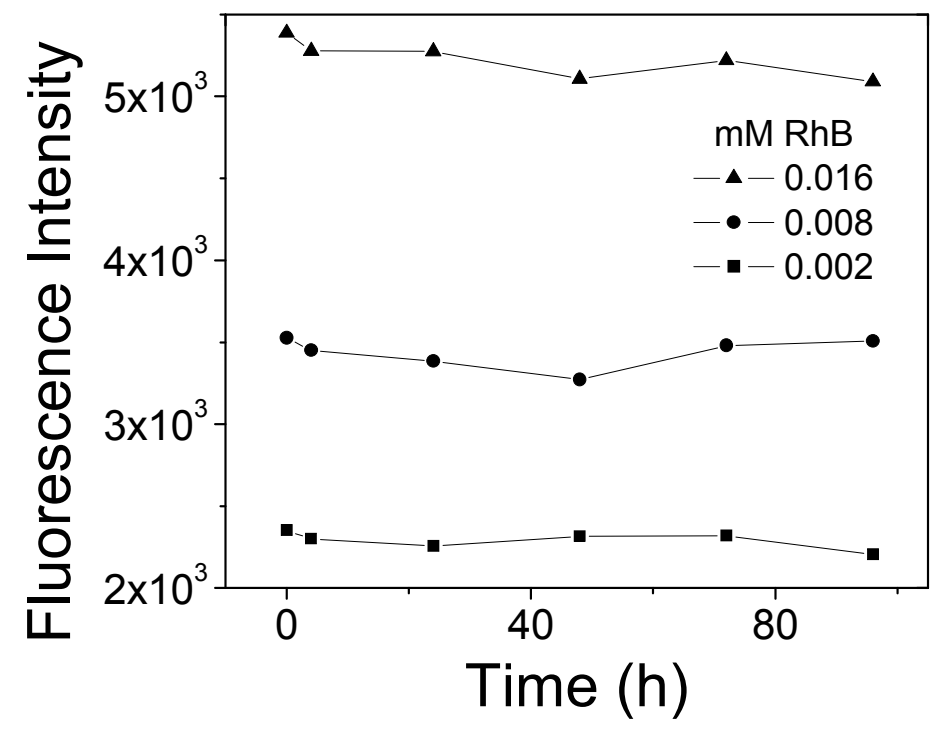

Supporting information 3: Fluorescence intensity of $\mathrm{RhB}$ as a function of time. For $96 \mathrm{~h}$ the fluorescence intensity remained constant without appreciable variation.

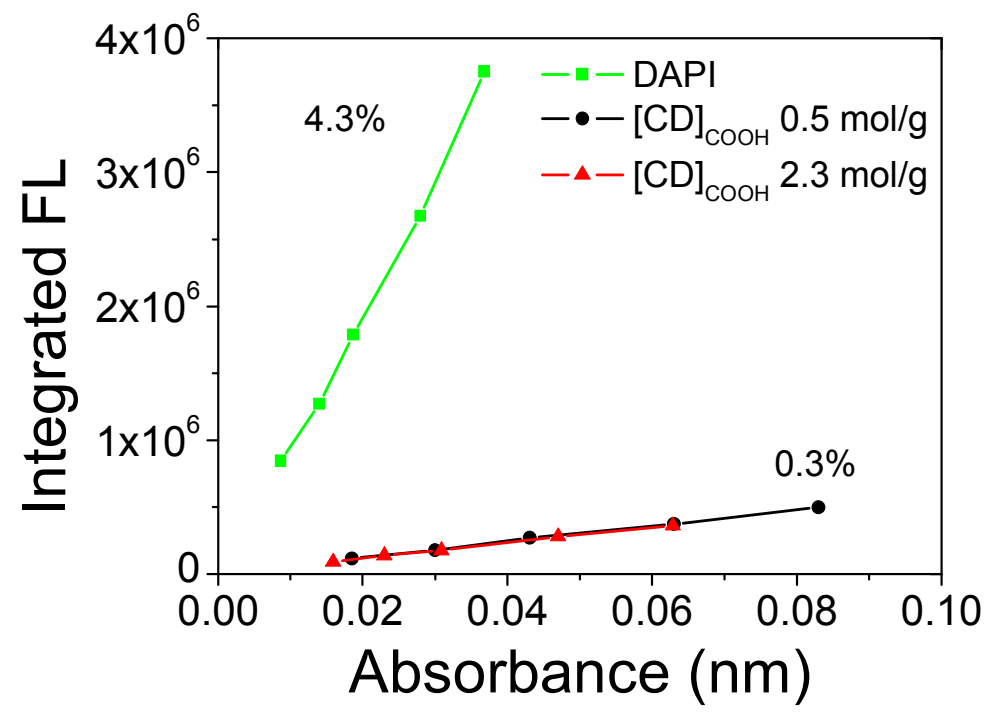

Supporting information 4: Quantum yield of both $[C D]_{\mathrm{COOH}} 2.3$ and $0.5 \mathrm{~mol} \mathrm{~g}^{-1} \mathrm{CDs}$ in water when using DAPI as standard $\left(\sim 4 \%{ }^{1}\right)$. 


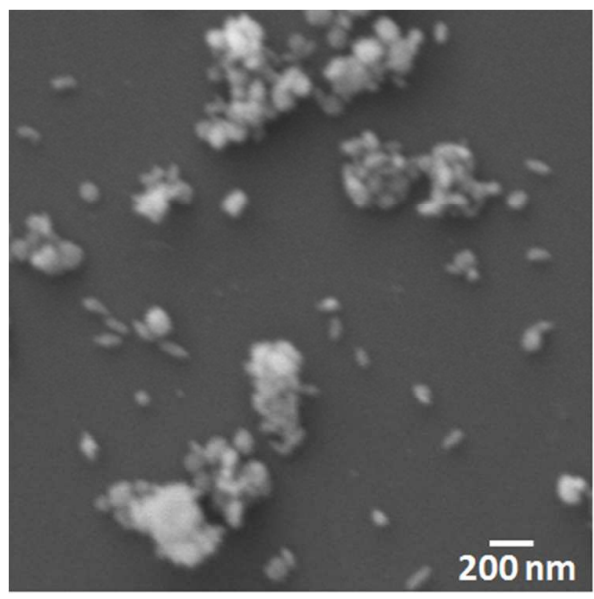

Supporting information 5: SEM of CD-CaCO3 synthesized at $1.4 \mathrm{~g} \mathrm{~L}^{-1}$ PAA. Very small nanoparticles (under $90 \mathrm{~nm}$ ) are stabilized by the high polymer concentration which hinders aggregation.

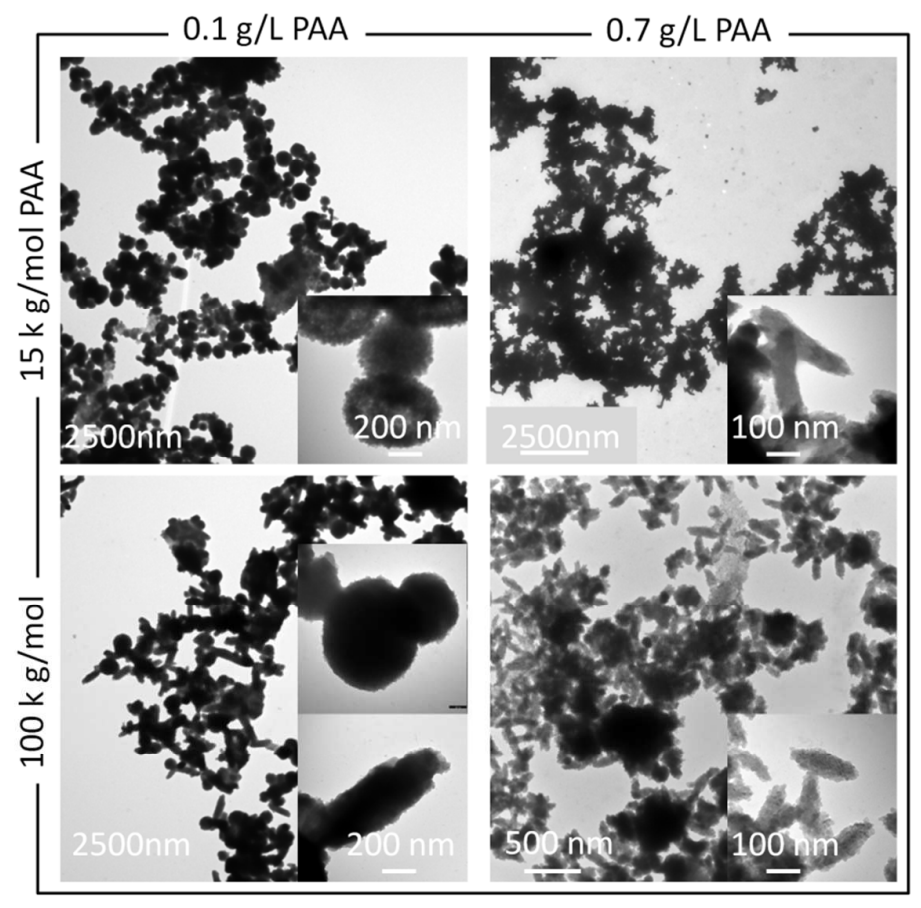

Supporting information 6: TEM micrographs as an overview of $\mathrm{CD}-\mathrm{CaCO}_{3}$ synthesized with $15 \mathrm{k}$ and $100 \mathrm{~kg} / \mathrm{mol}$ PAA at 0.15 and $0.7 \mathrm{~g} / \mathrm{L}$ of PAA. Samples were mineralized with $\mathrm{CD}_{\mathrm{COOH}} 2.3 \mathrm{~g} / \mathrm{mol}$. 

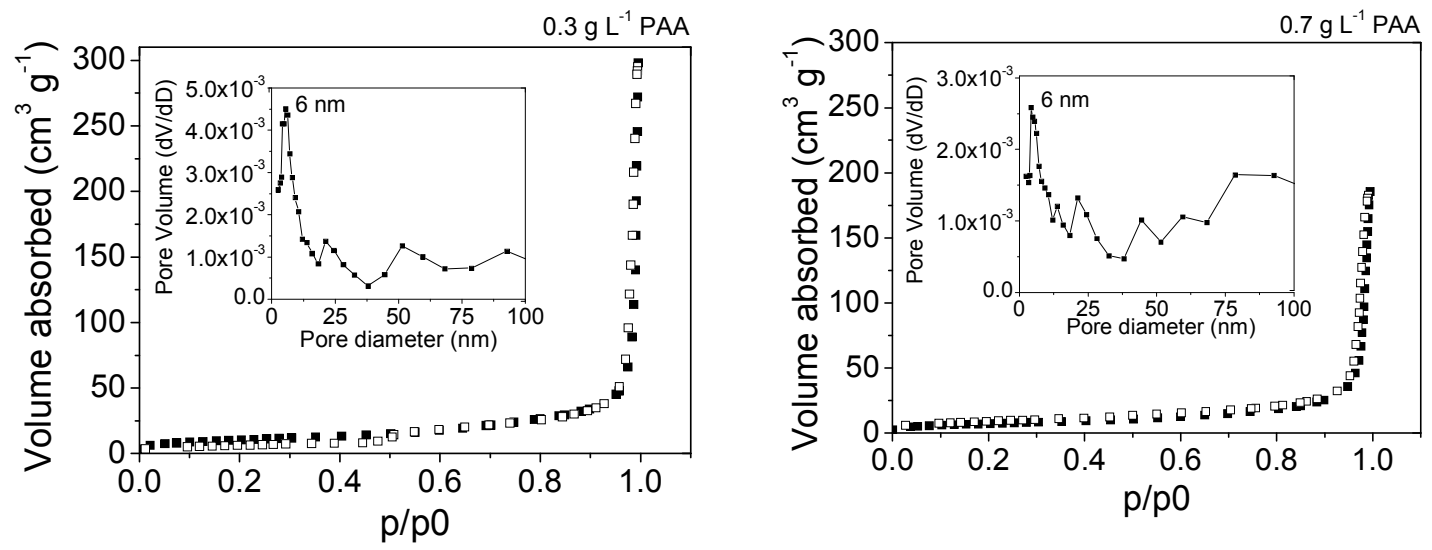

Supporting information 7. Nitrogen adsorption-desorption of 0.3 and $0.7 \mathrm{~g} / \mathrm{L}$ PAA samples. Pore size distribution calculated by BJH shows a monomodal (about $6 \mathrm{~nm}$ ) distribution of pores.

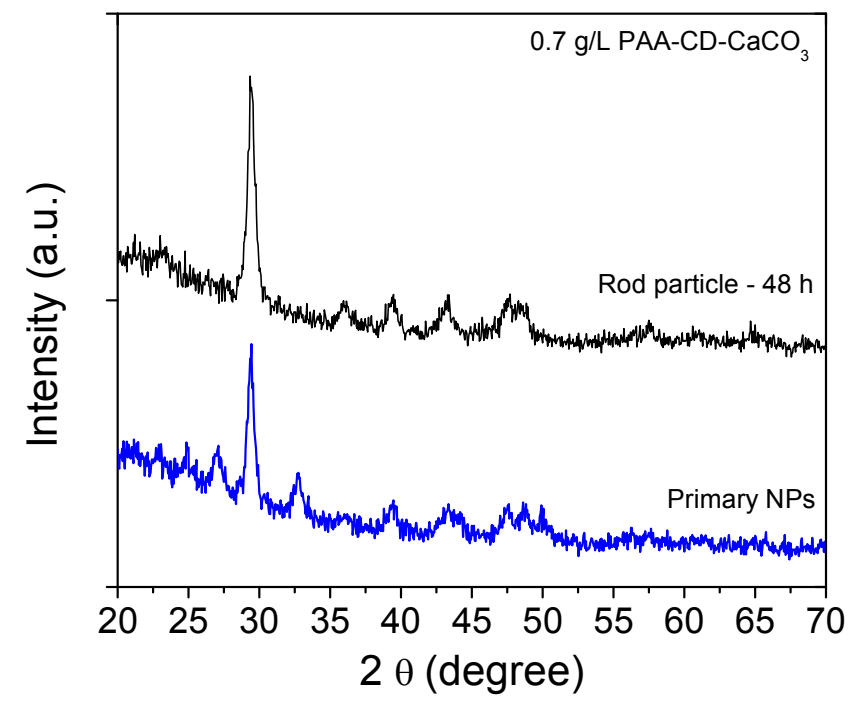

Supporting information 8. XRD patterns of PAA-CD-CaCO ${ }_{3}$ immediately after synthesis and after $48 \mathrm{~h}$. PAA concentration is $0.7 \mathrm{~g} / \mathrm{L}$. 


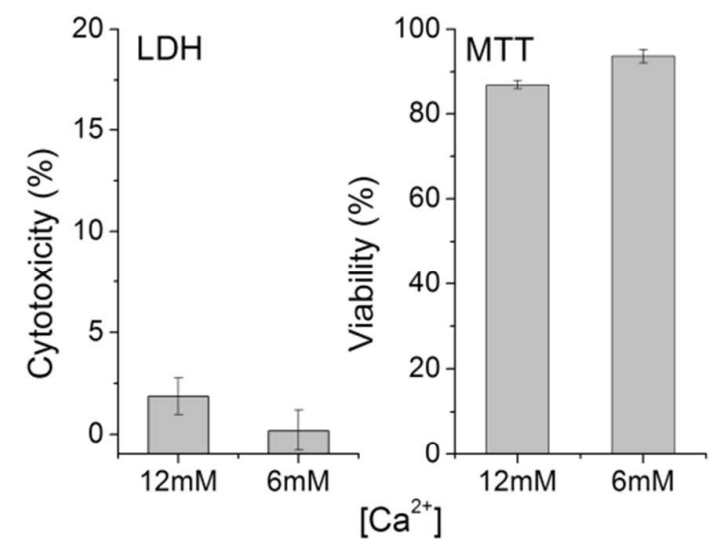

Supporting information 9. Evaluation of $\mathrm{Ca}^{2+}$-induced cytotoxicity assessed by means of LDH and MTT assay.

\section{References:}

(1) Li, M.; Wu, R. S.; Tsai, J. S. C. DAPI Derivative: A Fluorescent DNA Dye That Can Be Covalently Attached to Biomolecules. Bioorganic Med. Chem. Lett. 2003, 13, 4351-4354. 